University of Nebraska - Lincoln

DigitalCommons@University of Nebraska - Lincoln

2012

\title{
Large-eddy/Reynolds-averaged Navier-Stokes simulation of a supersonic reacting wall jet
}

Jack R. Edwards

North Carolina State University at Raleigh

John A. Boles

Taitech Inc., WP AFB, $\mathrm{OH}$

Robert A. Baurle

NASA Langley Research Center, Hampton, VA

Follow this and additional works at: https://digitalcommons.unl.edu/nasapub

Part of the Physical Sciences and Mathematics Commons

Edwards, Jack R.; Boles, John A.; and Baurle, Robert A., "Large-eddy/Reynolds-averaged Navier-Stokes simulation of a supersonic reacting wall jet" (2012). NASA Publications. 52.

https://digitalcommons.unl.edu/nasapub/52

This Article is brought to you for free and open access by the National Aeronautics and Space Administration at DigitalCommons@University of Nebraska - Lincoln. It has been accepted for inclusion in NASA Publications by an authorized administrator of DigitalCommons@University of Nebraska - Lincoln. 


\title{
Large-eddy/Reynolds-averaged Navier-Stokes simulation of a supersonic reacting wall jet
}

\author{
Jack R. Edwards ${ }^{\text {a,* }}$, John A. Boles ${ }^{b}$, Robert A. Baurle ${ }^{c}$ \\ a Department of Mechanical and Aerospace Engineering, Campus Box 7910, North Carolina State University, Raleigh, NC 27695, United States \\ ${ }^{\mathrm{b}}$ Taitech Inc., Blsdg. 18-D, Room 235, WPAFB, OH 45433, United States \\ ${ }^{\mathrm{C}}$ Hypersonic Air-Breathing Propulsion Branch, Mail Stop 168, NASA Langley Research Center, Hampton, VA 23681-2199, United States
}

\section{A R T I C L E I N F O}

\section{Article history:}

Received 9 March 2011

Received in revised form 8 August 2011

Accepted 8 October 2011

Available online 31 October 2011

\section{Keywords:}

Supersonic combustion

Large-eddy simulation

\begin{abstract}
A B S T R A C T
This work presents results from large-eddy/Reynolds-averaged Navier-Stokes (LES/RANS) simulations of the well-known Burrows-Kurkov supersonic reacting wall-jet experiment. Generally good agreement with experimental mole fraction, stagnation temperature, and Pitot pressure profiles is obtained for non-reactive mixing of the hydrogen jet with a non-vitiated air stream. A lifted flame, stabilized between 15 and $20 \mathrm{~cm}$ downstream of the hydrogen jet, is formed for hydrogen injected into a vitiated air stream. Flame stabilization occurs closer to the hydrogen injection location when a three-dimensional combustor geometry (with boundary layer development resolved on all walls) is considered. Volumetric expansion of the reactive shear layer is accompanied by the formation of large eddies which interact strongly with the reaction zone. Time averaged predictions of the reaction zone structure show an under-prediction of the peak water concentration and stagnation temperature, relative to experimental data, but display generally good agreement with the extent of the reaction zone. Reactive scalar scatter plots indicate that the flame exhibits a transition from a partially-premixed flame structure, characterized by intermittent heat release, to a diffusion-flame structure that could probably be described by a strained laminar flamelet model.
\end{abstract}

(c) 2011 Published by Elsevier Inc. on behalf of The Combustion Institute.

\section{Introduction}

Combustion processes occurring in high-speed propulsion devices can be strongly impacted by finite-rate chemistry and turbulence/chemistry interactions, as well as by large-scale unsteady behavior caused by intermittent ignition events, shock/boundary layer interactions, and vortex dynamics. The state of the practice in high-speed engine component simulations [1] solves the Reynolds-averaged Navier-Stokes (RANS) equations, expanded to include separate equations for species transport. Closure is usually accomplished through two-equation turbulence models in conjunction with Boussinesq and gradient-diffusion assumptions. Chemical reaction source terms are usually formulated using the law of mass action, and the effects of turbulence fluctuations on reaction rates are either completely ignored or modeled via eddy break up or assumed PDF methods. This standard model, once calibrated, has been used successfully in the design of scramjetpowered vehicles such as NASA's Hyper-X, the University of Queensland's HyShot program, and the US Air Force's Scramjet Engine Demonstrator, but the ability of the model to handle highly

\footnotetext{
* Corresponding author. Fax: +1 9195157968.

E-mail address: jredward@ncsu.edu (J.R. Edwards).
}

transient physics of the types mentioned above is questionable at best.

High-fidelity methods, such as large-eddy simulations (LES) or hybrid large-eddy/Reynolds-averaged Navier-Stokes (LES/RANS) simulations, offer some promise for improvement but come with their own complications. Some of the more sophisticated closure strategies (filtered masss density function (FMDF) methods [2], conditional moment closure (CMC) [3], one-dimensional turbulence (ODT) [4]) are capable of handling finite-rate chemical kinetics but are expensive and often employ low-Mach number assumptions that may restrict their applicability. Flamelet-type and reaction progress variable closures $[5,6]$ may also have difficulty for supersonic combustion as pressure changes along a streamline and kinetic-energy influences are typically neglected in the flamelet description of the energy equation. Some prior work in applying large-eddy simulation methods to supersonic combustion problems has been reported in Genin et al. [7,8] and Berglund and Fureby [9], who simulated hydrogen-air combustion behind a wedge-shaped flameholder using linear-eddy [10] and flamelettype subgrid combustion models. In general, reasonable agreement with experimental temperature and velocity profiles [11] was obtained. In a later study, Berglund et al. [12] considered a range of turbulent combustion models and several simple subgrid closures 
(including a 'laminar chemistry' formulation that neglects effects of subgrid fluctuations on species production rates) in their simulations of supersonic combustion in a configuration studied at ONERA/JAXA. They found better agreement with experimental OH-PLIF images when a seven-step finite rate chemistry mechanism was employed, but the effects of the various subgrid closures considered were inconclusive. Peterson and Candler [13,14] applied a detached-eddy simulation method with 'laminar chemistry' to the SCHOLAR supersonic-combustion experiment [15] and reported reasonable agreement with wall pressure distributions and experimental CARS images. In a more recent work, Donde et al. [16] applied a direct-quadrature method of moments (DQMOM) closure to several supersonic combustion problems. They used a two-environment Eulerian model to discretize the FDF governing subgrid-scale mixing and combustion, essentially doubling the computational cost relative to a 'laminar chemistry' formulation.

Supersonic combustion processes in engine-type geometries often involve interactions between flames and boundary layers developing on multiple solid surfaces. Wall turbulence, often influenced by multiple shock interactions, can significantly impact flame propagation, as can heat transfer to the walls. In this work, we employ a recently-developed hybrid large-eddy simulation/ Reynolds-averaged Navier Stokes (LES/RANS) method [17] to account for the effects of resolved wall turbulence on the development of a supersonic, reacting wall jet in a wind tunnel. The experiment is that of Burrows and Kurkov [18,19], in which vitiated air is passed through a Mach 2.5 nozzle into a stepped-wall combustor, where it mixes with sonic hydrogen injected through a vertical slot (Fig. 1). The experiments provide data for inert gas mixing (in which nitrogen gas is used to replace oxygen in the air stream) and mixing followed by combustion (with oxygen present in the air stream).

The Burrows-Kurkov database is extensive, including surveys of Pitot pressure and stagnation temperature, gas-sampling mole fraction measurements, ignition onset locations (obtained from ultraviolet imaging), and wall pressure measurements, making it a popular choice for the validation of RANS models for supersonic combustion [20-24]. In general, accurate predictions of the timeaveraged reactive scalar profiles (obtained experimentally through gas-sampling) can be achieved using such models. In some cases, this is through a trial and error procedure, as the predicted location of the flame is sensitive to the assumed state of the incoming boundary layer, the choice of hydrogen-air oxidation mechanism, and the type of turbulence closure involved. It is an open question whether a more 'high fidelity' method, such as LES or LES/RANS,

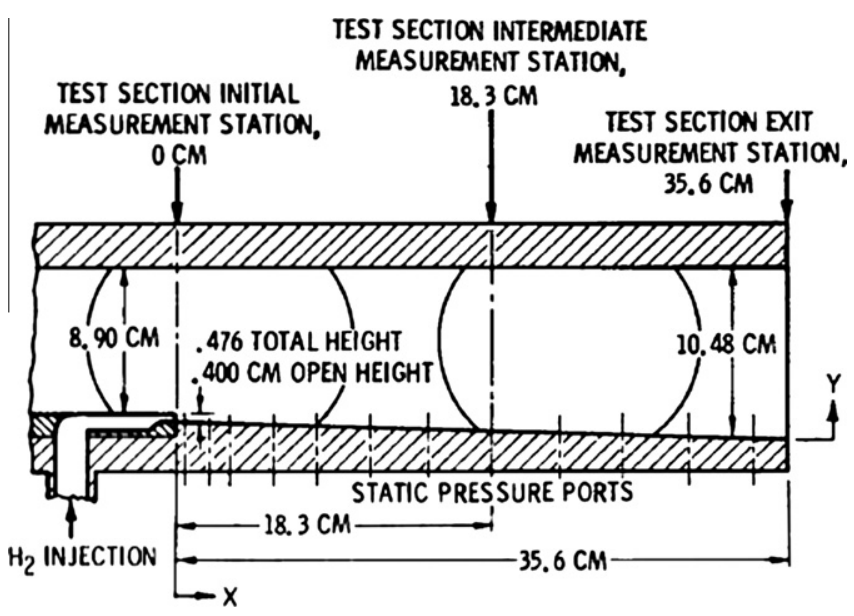

Fig. 1. Schematic of Burrows and Kurkov combustor (from Ref. [18]). can provide equivalent or better predictions. The major problem with the Burrows-Kurkov database is that the boundary conditions cannot be specified precisely, as the geometry of the wind tunnel that provides the vitiated air to the combustor section is not given in the reports. One must idealize the inflow in some fashion, and there is not enough data to assess some factors, such as the growth rate of boundary layers on the sides of the combustor.

This paper describes LES/RANS simulations of the Burrows and Kurkov supersonic combustion experiment, obtained on domains with periodic boundary conditions imposed and on fully 3D domains that also capture the time-dependent growth of boundary layers on the top and side walls of the combustor. The effects of the choice of reaction mechanism are examined, and the relative influences of two simplified closures for the filtered species production rates are described.

\section{Numerical formulation}

\subsection{Thermodynamic model}

The computational model used in this investigation solves the Navier-Stokes equations governing a mixture of thermally-perfect gases. A seven-species gas model for hydrogen oxidation $[25,26]$ is used for most calculations. A nine-species model [27] is used for one calculation. Thermodynamic curve fits from McBride et al. [28] are used for species specific heats and enthalpies. Wilke's law is used for the mixture viscosity, and the mixture thermal conductivity is obtained from the assumption of a constant Prandtl number (0.72). Molecular diffusion processes are described using Fick's law, parameterized by a constant Schmidt number of 0.5. The law of mass action is used to formulate source terms describing production/depletion of chemical species.

\subsection{Turbulence model}

The turbulence model used in this work is a hybrid large-eddy simulation/Reynolds-averaged Navier-Stokes (LES/RANS) technique first presented in [17] and evaluated for several high-speed wall-bounded flows in [29-31]. In this strategy, the RANS model (Menter's k- $\omega$ [32]) is used as a near-wall closure within an overall large-eddy simulation framework. A model constant that controls the location of the RANS-to-LES region within a boundary layer is calculated to be 22.17 using procedures described in [17, 29]. Conditions within the Burrows/Kurkov combustor are such that the LES model is used for $\sim 95 \%$ of the flow. The subgrid model used for the LES is an algebraic form from Lenormand et al. [33]:

$v_{t, \mathrm{sgs}}=C_{M} S^{1 / 2}\left(q^{2}\right)^{1 / 4} \Delta^{3 / 2}, C_{M}=0.06$,

with

$S=\left[\frac{\partial \tilde{u}_{i}}{\partial x_{j}} \frac{\partial \tilde{u}_{j}}{\partial x_{i}}+\frac{\partial \tilde{u}_{i}}{\partial x_{j}} \frac{\partial \tilde{u}_{i}}{\partial x_{j}}-\frac{2}{3}\left(\frac{\partial \tilde{u}_{k}}{\partial x_{k}}\right)^{2}\right]^{1 / 2}$.

An estimate of the subgrid kinetic energy is obtained by test-filtering the resolved-scale velocity data,

$q^{2}=\frac{1}{2}\left(\tilde{u}_{m}-\tilde{\tilde{u}}_{m}\right)^{2}$,

with $\tilde{\tilde{u}}_{m}$ determined using a simple box-averaging procedure in computational space:

$$
\begin{aligned}
\tilde{\tilde{u}}_{m}= & \frac{1}{2} u_{m i, j, k}+\frac{1}{12}\left(u_{m i+1, j, k}+u_{m i-1, j, k}+u_{m i, j+1, k}+u_{m i, j-1, k}\right. \\
& \left.+u_{m i, j, k+1}+u_{m i, j, k-1}\right) .
\end{aligned}
$$

Closures for turbulent heat-flux and diffusion terms are standard gradient-diffusion formulations, parameterized respectively by 
constant values of the turbulent Prandtl number (0.9) and the turbulent Schmidt number $(0.5)$.

A major concern in large-eddy simulation of reactive flows is the closure for the filtered species production rates, which are nonlinear functions of temperature and species density (denoted as the vector $V=\left[\rho_{k}, T\right]^{T}$ in the discussion that follows). Though various sophisticated models have been proposed [2-4,6,10], we opt for simpler strategies that utilize only information contained in the resolved fields and do not expand the dimension of the problem space. The first closure, used for the majority of the calculations, evaluates the species production rates using cell-averaged (grid filtered) data (the 'laminar chemistry' assumption):

$\overline{\dot{\omega}_{s}(V)}=\dot{\omega}_{s}(\bar{V}) \equiv \dot{\omega}_{s}\left(\bar{\rho}_{s}, \tilde{T}\right)$

To account for sub-cell effects on the evaluation of the chemical production terms, we adopt techniques conventionally used to extend finite volume methods to higher-order spatial accuracy. The approach is motivated by the finite-scale truncation-error analysis of Margolin and Shashkov [34], which connects a general filtered mean operator $\overline{f(\varphi)}$ to the operator evaluated using filtered mean data $f(\bar{\varphi})$. Their analysis presumes that the filtered fields (regardless of scale) are smooth enough to allow a convergent Taylor expansion. Extending this idea to the chemical production terms requires first a local estimate of the variation of the grid-filtered solution within a mesh cell. This may be obtained from Taylor expansion about the cell-averaged (grid-filtered) mean data $\bar{V}$

$V_{R}(\vec{x})=\bar{V}+\left[\nabla \bar{V}+\frac{1}{2} \nabla\left(\nabla \bar{V} \cdot\left(\vec{x}-\vec{x}_{c}\right)\right)\right] \cdot\left(\vec{x}-\vec{x}_{c}\right)+\ldots$,

Evaluating this expression at a set of $n q$ Gaussian quadrature points $\vec{x}_{k}$ within a general mesh cell and requiring that the mean value be preserved according to

$\sum_{k=1}^{n q} w_{k} V_{R}\left(\vec{x}_{k}\right)=\Omega \bar{V}$

where $w_{k}$ is a set of quadrature weights and $\Omega$ is the cell volume, leads to the final form of the reconstruction polynomial $V_{R}$ :

$$
\begin{aligned}
V_{R}(\vec{x})= & \bar{V}+\left[\nabla \bar{V}+\frac{1}{2} \nabla\left(\nabla \bar{V} \cdot\left(\vec{x}-\vec{x}_{c}\right)\right)\right] \cdot\left(\vec{x}-\vec{x}_{c}\right) \\
& -\frac{1}{\Omega} \sum_{k=1}^{n q} w_{k}\left[\nabla \bar{V}+\frac{1}{2} \nabla\left(\nabla \bar{V} \cdot\left(\vec{x}_{k}-\vec{x}_{c}\right)\right)\right] \cdot\left(\vec{x}_{k}-\vec{x}_{c}\right) .
\end{aligned}
$$

From this, one evaluates the filtered chemical production term as

$\Omega \overline{\dot{\omega}_{s}}=\iiint_{\Omega} \dot{\omega}_{s}(V(\vec{x})) d \Omega \approx \sum_{k=1}^{n q} w_{k} \dot{\omega}_{s}\left(V_{R}\left(\vec{x}_{k}\right)\right)$.

This approach can be viewed as a second-order correction to the basic laminar-chemistry evaluation of the species production terms. It is also related to the scale-similarity filtered reaction-rate model (SSFRRM) of Desjardin and Frankel [35], where

$\overline{\dot{\omega}_{s}(V)} \approx \dot{\omega}_{s}(\bar{V})+\overline{\dot{\omega}_{s}(\bar{V})}-\dot{\omega}_{s}(\overline{\bar{V}})$.

Here, $V_{R}(\vec{x})$ can be viewed as a reconstruction of the continuous grid-filtered variable $\bar{V}(\vec{x})$, for which only cell-averages are available in the large-eddy simulation:

$\overline{\dot{\omega}_{s}(V)} \approx \dot{\omega}_{s}\left(\overline{V_{R}}\right)+\overline{\dot{\omega}_{s}\left(V_{R}\right)}-\dot{\omega}_{s}\left(\overline{\overline{V_{R}}}\right)$.

The interpretation of the filtering operator as volume integration over the mesh cell and the requirement that the mean value be preserved means that $\overline{\overline{V_{R}}}=\overline{V_{R}}=\bar{V}$, and the SSFRRM reduces to the filtered reaction-rate model (FRRM) also defined in [35]:

$\overline{\dot{\omega}_{s}(V)} \approx \overline{\dot{\omega}_{s}\left(V_{R}\right)}$.
Desjardin and Frankel utilize explicit filtering of cell-averaged quantities and thus can retain the additional terms in Eq. (10). Appendix A provides further details of the implementation of formulation, henceforth referred to as the 'Gaussian quadrature' closure.

The inflow boundary layer for the LES/RANS simulations is sustained through a recycling/rescaling technique, applied to the fluctuating fields $[17,29]$. For the calculations performed in the complete 3D combustor, periodic flow cannot be assumed, and a more general recycling/rescaling procedure [36], valid for flows affected by multiple walls, is used.

\subsection{Numerical discretization}

The Navier-Stokes equations are formulated in a cell-centered finite-volume manner and are solved on a simply-connected, multi-block structured mesh. Inviscid fluxes are discretized using a variant of the piecewise parabolic method (PPM [37]) along with Edwards' low diffusion flux splitting scheme (LDFSS) [38]. The primitive-variable vector $W=\left[p_{s}, u, v, w, T, k, \omega\right]^{T}$ is used in the reconstruction. If left- and right-state information based on simple averages is provided to LDFSS, the interface flux that results should be kinetic-energy-preserving in the sense of Jameson [39] and Subbareddy and Candler [40]. The initial step in the PPM reconstruction sets left- and right states to

$W_{L, i+1 / 2}^{A}=W_{R, i+1 / 2}^{A}=\frac{7}{12}\left(W_{i}+W_{i+1}\right)-\frac{1}{12}\left(W_{i+2}-W_{i-1}\right)$,

which yields a fourth-order central difference approximation on uniform meshes. Monotonicity is enforced by a cell-by-cell resetting of left and right states [37], leading to final left- and right-state values (superscript ' $M$ ') that are different from the averaged ones (superscript ' $A$ '). The amount of numerical dissipation added at a cell interface is proportional to the difference in left- and right-state values. While enforcing monotonicity helps in shock-capturing, it compromises the ability of the scheme to resolve small-scale turbulent structures. One means of alleviating this problem is to blend the averaged values (Eq. (13)) with the monotonicity-preserving values so that the former is used in regions of high vorticity (boundary layers, shear layers) and the latter is used in more 'inviscid' regions, where strong shocks might be present. A function due to Ducros et al. [41], defined at a mesh cell as

$$
\begin{aligned}
f & =\frac{(\nabla \cdot \vec{V})^{2}}{(\nabla \cdot \vec{V})^{2}+|\omega|^{2}+\varepsilon^{2}}, \\
\varepsilon & =1 \times 10^{-8} V_{\infty} / \max (\overline{\Delta x}, \overline{\Delta y}, \overline{\Delta z}),
\end{aligned}
$$

has been used to provide this switch in other such 'hybridization' strategies [40,42]. Here, the divergence of velocity is compared with the vorticity value. If the latter is much larger (in shear and boundary layers, for example), the function moves toward zero, and in free-stream regions near shocks, the function approaches one. At a particular cell interface $i+1 / 2$, we use the function as follows:

$$
\begin{aligned}
& W_{L, i+1 / 2}=W_{L, i+1 / 2}^{A}+\max \left(f_{i}, f_{i+1}, 0.1\right)\left(W_{L, i+1 / 2}^{M}-W_{L, i+1 / 2}^{A}\right) \\
& W_{R, i+1 / 2}=W_{R, i+1 / 2}^{A}+\max \left(f_{i}, f_{i+1}, 0.1\right)\left(W_{R, i+1 / 2}^{M}-W_{R, i+1 / 2}^{A}\right)
\end{aligned}
$$

This scheme, denoted as LD-PPM for low-dissipation PPM, is used for all calculations presented in this paper. Viscous and diffusive terms appearing in the equation system are discretized using second-order central differences. 


\subsection{Time advancement}

Time integration is facilitated by a planar relaxation sub-iteration procedure based on a Crank-Nicholson - type discretization of the unsteady equations. The specific form used is

$\Omega \frac{U^{n+1, k}-U^{n}}{\Delta t}+\frac{1}{2}(1+\theta) R\left(V^{n+1, k}\right)+\frac{1}{2}(1-\theta) R\left(V^{n}\right)=0$,

where $\Omega$ is the cell volume, $\Delta t$ is the time step (set to $1 \mathrm{e}-7 \mathrm{~s}$ for all cases presented), $U$ is the vector of conserved variables, and $R$ is the residual vector. The function $\theta$ is defined as

$\theta=\frac{1}{2}\left(1-\tanh \left(\frac{d-d_{t}}{\Delta d}\right)\right), \quad d_{t}=1 \times 10^{-4} \mathrm{~m}, \quad \Delta d=0.2 d_{t}$.

Here, $d$ is the distance to the nearest solid surface. The function $\theta$ switches the time discretization from Crank-Nicholson to Euler implicit for mesh cells essentially within the laminar sub-layer. Some loss of temporal accuracy results, but this approach appears necessary to suppress oscillations in the pressure and transverse-velocity fields for mesh cells with a very high aspect ratio. The code is parallelized using domain-decomposition/MPI message-passing methods. Jacobian matrix elements are stored over the number of blocks mapped to a particular processor, allowing the "freezing" of the matrix elements and their factorization over the duration of the sub-iterations. This reduces the computational workload significantly.

\subsection{Computational grids, initial conditions, and boundary conditions}

Three meshes are used for the calculations. The first mesh, used for statistically 2D calculations, contains $11,643,456$ cells and extends $\pm 3.74 \mathrm{~cm}$ in the spanwise direction. Periodic boundary conditions are applied in the spanwise $(Z)$ direction for these calculations. The calculation that accounts for boundary layer development on the sidewalls also utilizes a mesh that contains $11,643,456$ cells. This mesh is clustered to the sidewalls and spans the exact width of the combustor $( \pm 2.5 \mathrm{~cm})$ while maintaining the same mesh spacing near the $X-Y$ centerplane as the other mesh. Mesh sensitivity is assessed by performing one calculation on a mesh that doubles the number of cells in the nominal streamwise direction (the ' $i$ ' computational coordinate for each of the mesh blocks). The first mesh is used as the basis for the refined mesh, which contains $23,286,912$ cells. The minimum cell spacing at all solid surfaces is $0.005 \mathrm{~mm}$. In the absence of details of the windtunnel geometry, a simulation of flow over a $1 \mathrm{~m}$ flat plate is used to generate an initial boundary layer of about $1 \mathrm{~cm}$ thick at the entrance of the combustor for the statistically 2D calculations. An analogous simulation of flow in a rectangular channel is used to generate the inflow plane for the calculation with resolved sidewall boundary layers. The nominal flow conditions as applied at the beginning of the flat plate and within the hydrogen jet nozzle are listed in Table 1.

Table 1

Reference conditions for Burrows/Kurkov experiments.

\begin{tabular}{lll}
\hline Property & Inert gas & Vitiated air \\
\hline$U_{\infty}(\mathrm{m} / \mathrm{s})$ & 1781.0 & 1741.4 \\
$T_{\infty}(\mathrm{K})$ & 1130.0 & 1237.9 \\
$p_{\infty}(\mathrm{Pa})$ & 96000.0 & 96000.0 \\
$Y_{\mathrm{N} 2}$ & 0.7324 & 0.486 \\
$Y_{\mathrm{O} 2}$ & 0.0509 & 0.258 \\
$Y_{\mathrm{H} 2}$ & 0.0005 & 0.000 \\
$Y_{\mathrm{H} 2 \mathrm{O}}$ & 0.2162 & 0.256 \\
$\mathrm{To}_{\mathrm{H} 2}(\mathrm{~K})$ & 314.0 & 314.0 \\
$\mathrm{Po}_{\mathrm{H} 2}(\mathrm{~Pa})$ & 216675.0 & 216675.0 \\
\hline
\end{tabular}

To initialize the LES/RANS solutions, two- and three-dimensional RANS solutions were first computed over a region of the combustor extending from $-0.1724 \mathrm{~m}$ upstream of the vertical hydrogen injection slot to $0.4 \mathrm{~m}$ downstream of the slot. A turbulent fluctuation field obtained from a previous calculation and rescaled to conform to the combustor domain was superimposed onto the flat-plate/channel region upstream of the fuel injector.

The time for data collection after the tunnel starts is listed as being $2.5 \mathrm{~s}$, so there is not enough time for the walls to reach a steady-state or adiabatic condition. A procedure that uses the time constant of the material to estimate a penetration depth of the heating load is thus employed [43]. The time constant is defined as

$t_{c}=\frac{d_{p}^{2} \rho_{s} C_{p, s}}{k_{s}}$

and given an estimated exposure time of $2.5 \mathrm{~s}$ and values for density, specific heat, and thermal conductivity of copper, the depth of penetration can be estimated as being $d_{p}=0.017 \mathrm{~m}$. The boundary condition applied along the combustor surfaces matches the heat flux from the fluid to the surface with that from the surface to a fictitious cell location $0.017 \mathrm{~m}$ inside the wall. This condition is used to calculate the temperature in ghost cells near walls according to

$\frac{1}{2}\left(T_{g}+T_{I}\right)=\frac{\left(T_{I}+\phi T_{w}\right)}{(1+\phi)}, \quad \phi=\frac{k_{s} \Delta n}{k_{f} d_{p}}, T_{w}=300 \mathrm{~K}$,

where $k_{s}$ is the thermal conductivity of copper, $k_{f}$ is the thermal conductivity of the fluid at the wall, and $\Delta n$ is the distance from the center of a cell adjacent to the wall to the wall itself. The inflow boundary condition for the hydrogen jet fixes the stagnation pressure and temperature to values of $216,675 \mathrm{~Pa}$ and $314 \mathrm{~K}$ respectively.

The LES/RANS simulations were run for a minimum of 15 flowthrough times $(0.0033 \mathrm{~s})$, with one flow-through time being that required for a particle at the nominal free-stream velocity of $1781 \mathrm{~m} / \mathrm{s}$ to traverse the $0.4 \mathrm{~m}$ extent of the combustor. Statistics were taken for the last 10 flow through times $(0.0022 \mathrm{~s})$. To compare with experimental probe data, the flow properties are averaged in time as well as over a defined region in the spanwise $(Z)$ direction. In cases where periodic boundary conditions are applied in the $Z$ direction, the averaging region is the entire spanwise expanse of the combustor $(Z= \pm 3.74 \mathrm{~cm})$. In cases where sidewall boundary layers are resolved, the averaging region is over $Z= \pm 1.3 \mathrm{~cm}$ to prevent flow-property variations within these boundary layers from affecting the averages.

\section{Results}

Table 2 summarizes the different types of simulations performed. LES/RANS calculations involving both inert-gas mixing and combustion were performed on the periodic domain. Reactive LES/RANS calculations were performed on the 3D domain.

\subsection{Inert-gas mixing - comparisons with experimental data}

Stagnation temperature and Pitot pressure distributions at locations near the entrance to the combustor $(X=0.0 \mathrm{~m})$ and its exit $(X=0.354 \mathrm{~m})$ are shown in Figs. 2 and 3 for the inert-gas mixing case. Predictions at the combustor entrance are actually for the vitiated-air condition (Table 1), as data is unavailable at this location for the inert-gas mixing conditions. Good agreement with experimental stagnation temperature and Pitot pressure distributions is indicated at the entrance location near the lower wall. This is not surprising, as the inflow boundary layer in the computation is targeted to match the thickness of the boundary layer measured 
Table 2

Summary of cases.

\begin{tabular}{|c|c|c|c|}
\hline Case & Thermodynamic model & Computational domain & Turbulence-chemistry interaction model \\
\hline 1 & Inert-gas mixing & Periodic & - \\
\hline 2 & 7-species $\mathrm{H}_{2}$ oxidation & Periodic & Laminar chemistry \\
\hline 3 & 7-species $\mathrm{H}_{2}$ oxidation & $3 \mathrm{D}$ & Laminar chemistry \\
\hline 4 & 7-species $\mathrm{H}_{2}$ oxidation & Periodic & Gaussian quadrature \\
\hline 5 & 9-species $\mathrm{H}_{2}$ oxidation & Periodic & Laminar chemistry \\
\hline 6 & 7-species $\mathrm{H}_{2}$ oxidation & Periodic, streamwise mesh refinement & Laminar chemistry \\
\hline
\end{tabular}

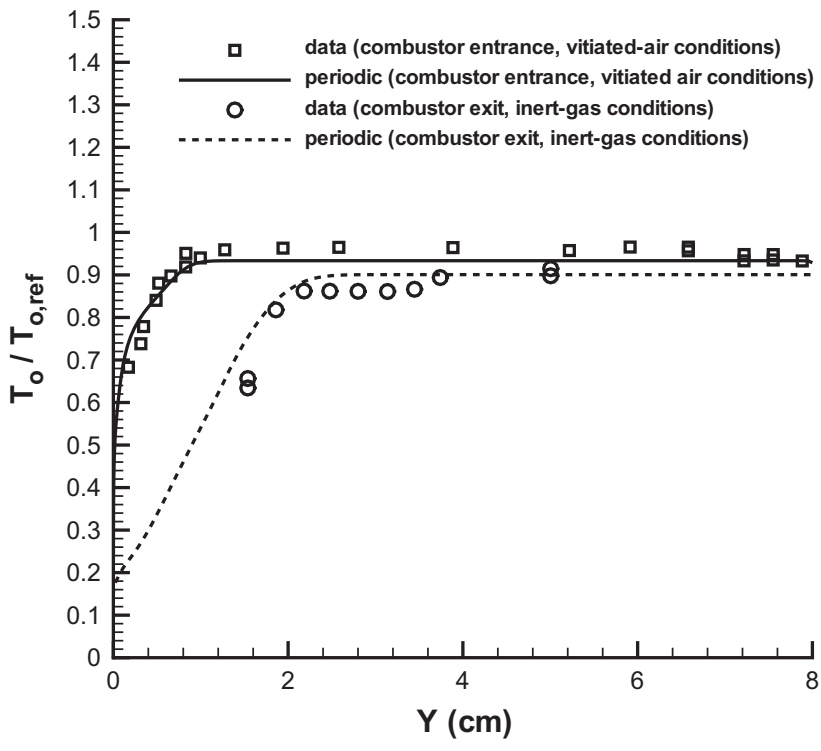

Fig. 2. Stagnation temperature profiles (inert-gas mixing).

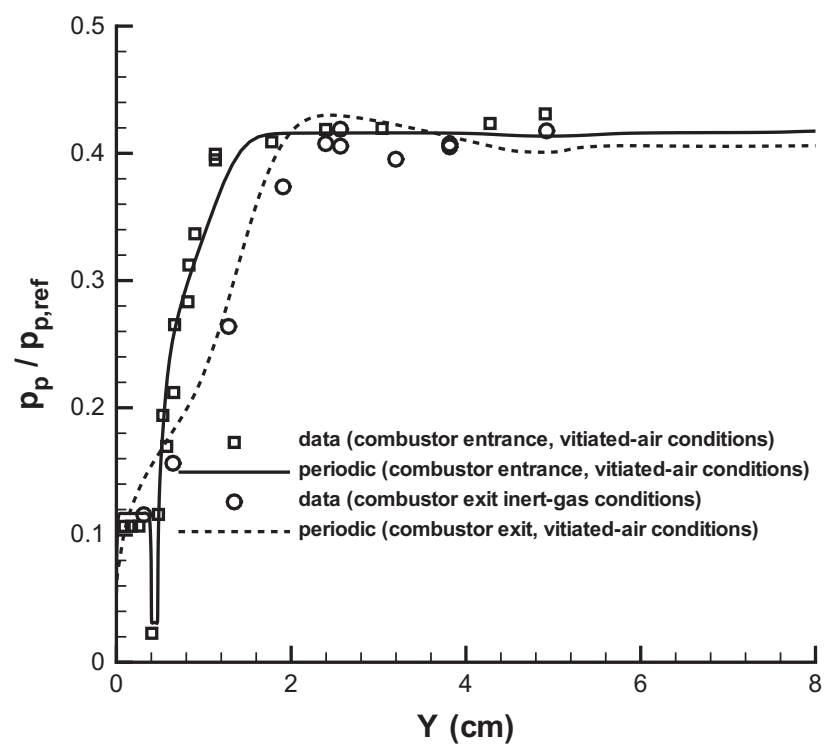

Fig. 3. Stagnation pressure profiles (inert-gas mixing).

at this location. The predictions of Pitot pressure at the combustor exit (Fig. 3) are in good agreement with the experiment. Profiles of nitrogen, water, and hydrogen mole fraction are compared with experimental gas-sampling measurements in Fig. 4. Good agreement is observed, indicating that the larger eddies that account for the bulk of the mixing process are adequately resolved and sustained by the numerical scheme.

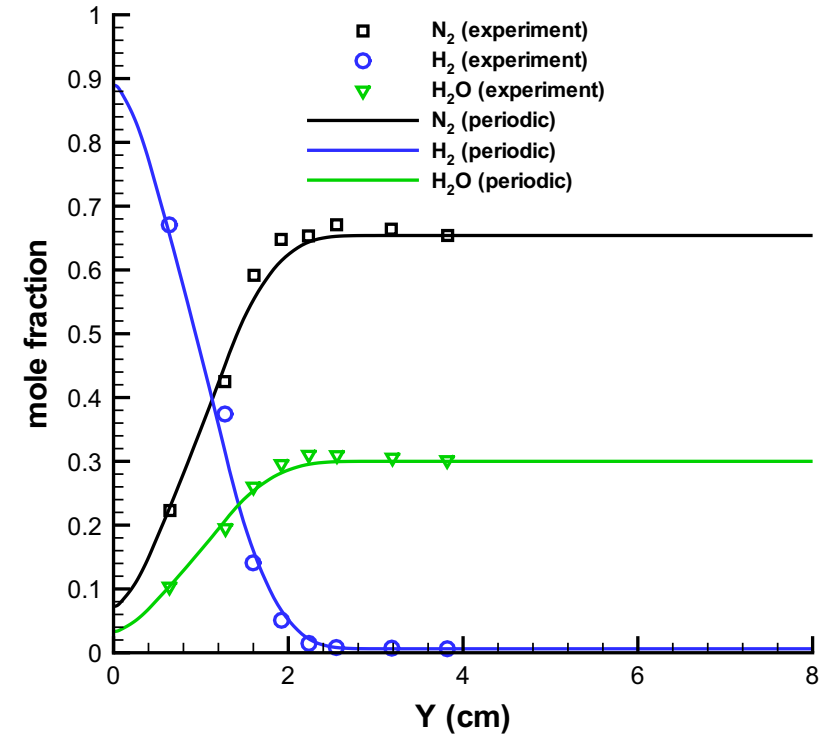

Fig. 4. Mole fraction profiles at combustor exit (inert-gas mixing).

\subsection{Inert-gas and vitiated-air mixing and combustion - flow features}

Snapshots of temperature and hydroxyl $(\mathrm{OH})$ mass fraction at the $X-Y$ centerplane of the combustor are shown in Figs. 5 and 6 for Cases 1-5 in Table 2. All reactive solutions show a lifted flame, stabilized between 15 and $20 \mathrm{~cm}$ downstream of the hydrogen injection position. A shock wave emanates from the flame stabilization location (Fig. 5). This results from the volumetric expansion of the shear layer due to heat release. The $\mathrm{OH}$ radical contours (Fig. 6) provide a marker for the flame-front location. Turbulent eddies clearly increase in size downstream of the stabilization position and are large enough to deform the reaction front, stretching the flame front. An induction zone of about $5 \mathrm{~cm}$ in length, characterized by the intermittent formation of pockets of fluid with high $\mathrm{OH}$ concentration but not substantial heat release, is noted in animations of the flame development. Downstream of the induction zone, pockets of strongly burning fluid, characterized by temperatures in excess of $2500 \mathrm{~K}$ and high water concentrations, intermix with pockets of cooler fluid through the action of resolved turbulent eddies. Differences among the models with regard to the stabilization position are slight, as shown in Fig. 7, a plot of timeaveraged temperature contours at the $X-Y$ centerplane. The flame is stabilized farthest upstream for Case 3 , which accounts for sidewall effects. The use of the Gaussian quadrature subgrid closure for the species production rates (Case 4) results in flame stabilization slightly upstream of the location predicted assuming laminar chemistry (Case 2). The use of the more detailed nine-species mechanism shifts the flame stabilization location downstream, relative to that provided by the seven-species model. The peak temperatures are concentrated in a slightly narrower band, indicating that the nine-species model promotes more reactivity at 


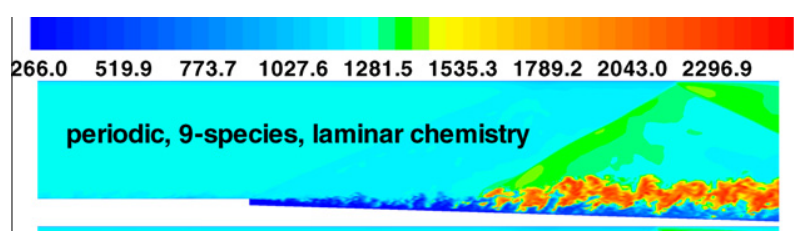

periodic, 7-species, Gaussian quadrature

-

3-D, 7-species, laminar chemistry

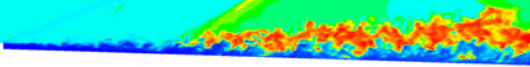

periodic, 7-species, laminar chemistry

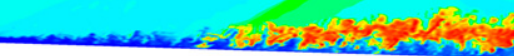

periodic, 7-species, laminar chemistry, streamwise mesh refinement
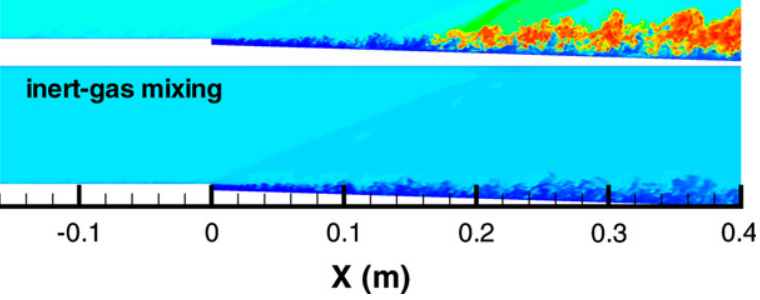

Fig. 5. Temperature contours at $X-Y$ centerplane (inert-gas mixing and vitiated-air mixing and combustion).

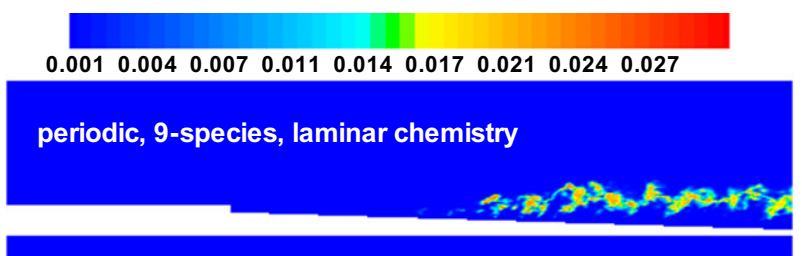

periodic, 7-species, Gaussian quadrature
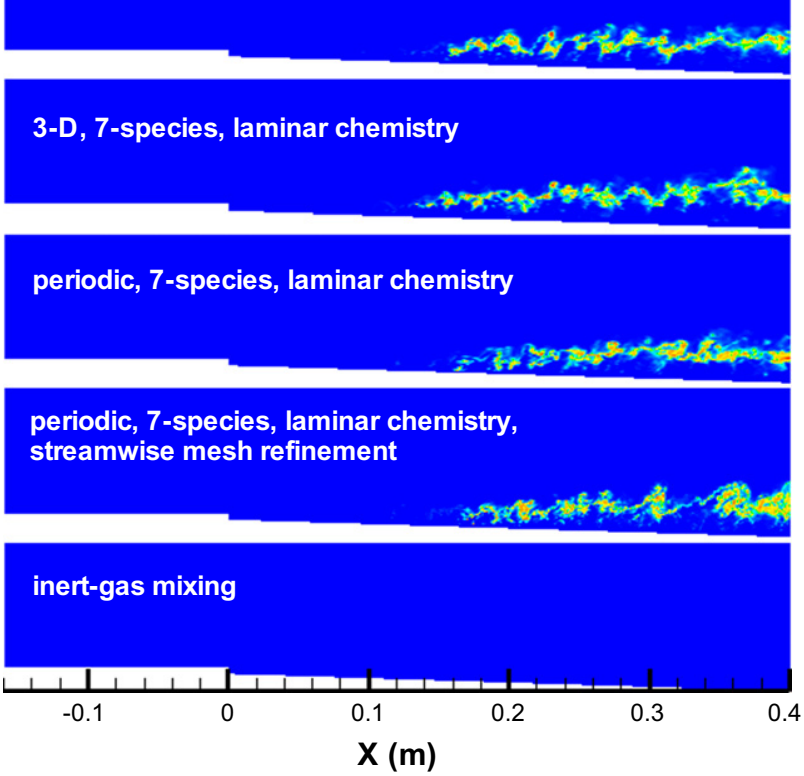

Fig. 6. $\mathrm{OH}$ mass fraction contours at $X-Y$ centerplane (inert gas mixing and vitiatedair mixing and combustion).

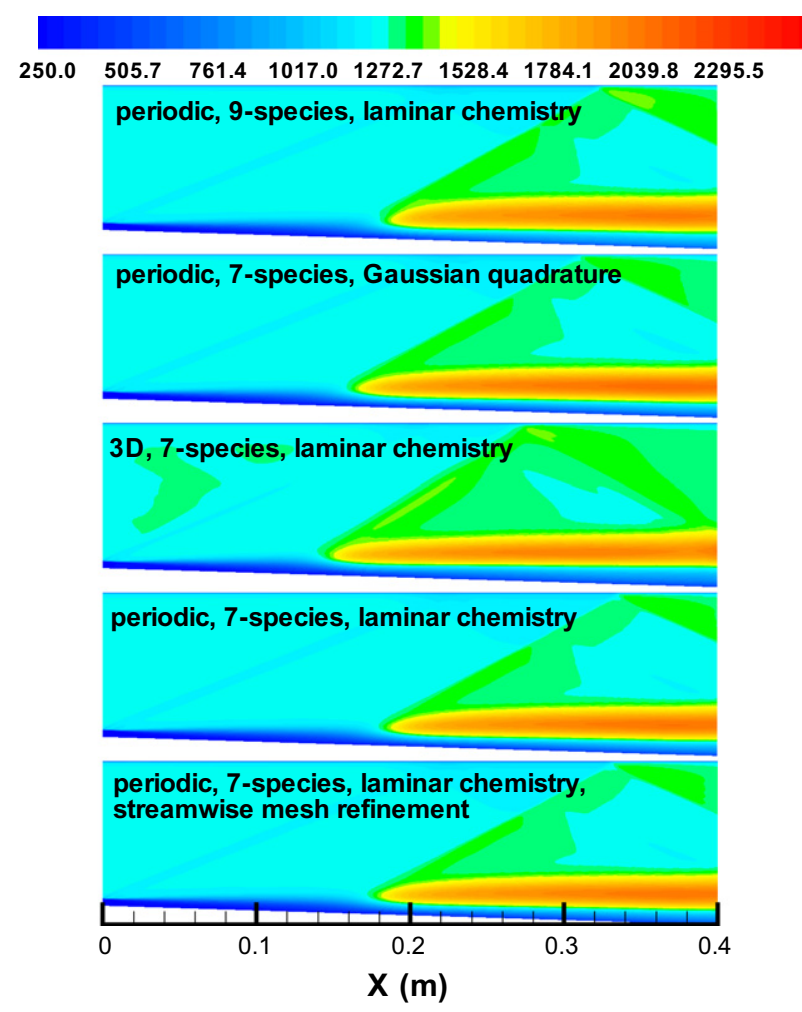

Fig. 7. Time- and span-averaged temperature contours (vitiated-air mixing and combustion).

the mesh scale. The flame thus becomes more resistant to straining effects induced by the larger turbulent eddies. Streamwise mesh refinement leads to the capturing of finer-scale turbulent structures (Figs. 5 and 6) but does not significantly affect the average temperature distribution (Fig. 7).

In the experiment, the lift-off height (termed the 'ignition length') is quantified as the onset of ultraviolet radiation as captured by ultraviolet-sensitive film. This distance ranges from between 11 and $27 \mathrm{~cm}$ downstream of the injector plane for an injectant temperature of $300 \mathrm{~K}$ and is a function of a 'local static temperature' determined as the average of free-stream inlet and exit temperatures. Unfortunately, no details of where, precisely, these temperatures were measured and what their values might be are found in [18], nor is the 'local static temperature' that corresponds to the nominal conditions (Table 1 ) of most of the sampling probe data given in the reference. It is therefore impossible to judge whether any of the cases considered correctly captures the lift-off distance, but it is clear that all of the computed lift-off positions are within the range of the experimental observations.

The swirl strength $\lambda_{C I}$ is defined as the imaginary portion of the complex eigenvalue of the local velocity gradient tensor. The higher the value of $\lambda_{c l}$, the shorter the time required for a fluid particle to swirl about a vortex core. Higher values of $\lambda_{c I}$ typically correspond to smaller-scale turbulent structures, and the distribution of $\lambda_{c I}$ can provide an approximate measure of the distribution of the sizes of turbulent eddies. Figure 8 shows a plot of the probability density function of the logarithm of the swirl strength versus streamwise distance for the inert-gas mixing and nine-species reacting cases. Upstream of the ignition point $(X=0.2 \mathrm{~m})$, the distributions are similar, with the most probable value of the swirl strength at the end of the domain for the non-reactive case equal to $\lambda_{c l} \sim 10^{4.54}=34,673 \mathrm{~s}^{-1}$. The effect of heat release is to shift the probability density function to lower values of the swirl strength. An increase in the population of larger eddies due to 


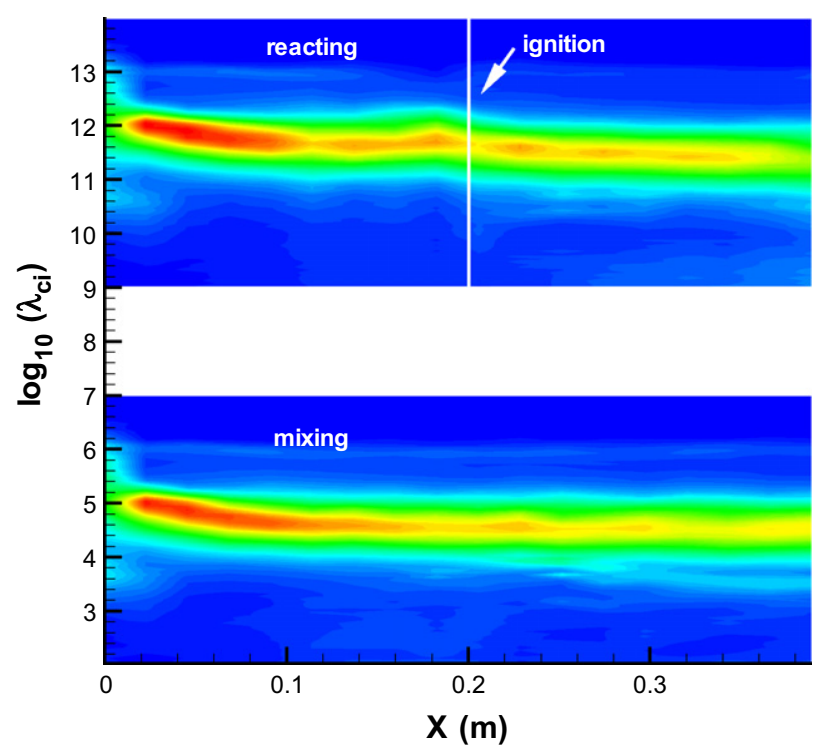

Fig. 8. Swirl strength probability density functions versus distance.

volumetric expansion and a decrease in the population of smaller eddies due to higher viscosities combine to produce this effect. The most probable value of the swirl strength at the end of the domain for the reactive case is $\lambda_{c l} \sim 10^{4.36}=22,908 \mathrm{~s}^{-1}$. Figure 9 shows iso-surfaces of the most probable swirl strength for the non-reactive case $\left(\lambda_{c I}=10^{4.54}\right)$, colored by temperature, for the mixing and reacting cases. Clearly indicated is the volumetric expansion of the shear layer after ignition.

Figure 10 shows time-averaged and instantaneous contours of a flame index [44] defined as $\left(\nabla Y_{\mathrm{H} 2} \cdot \nabla Y_{\mathrm{O} 2}\right) /\left(\left|\nabla Y_{\mathrm{H} 2}\right|\left|\nabla Y_{\mathrm{O} 2}\right|\right)$. This quantity is only evaluated where the average heat release (indicated in the topmost figure) exceeds $1 \%$ of its maximum value. The flame index distinguishes between non-premixed combustion (a negative flame index, as fuel and oxidizer approach the flame
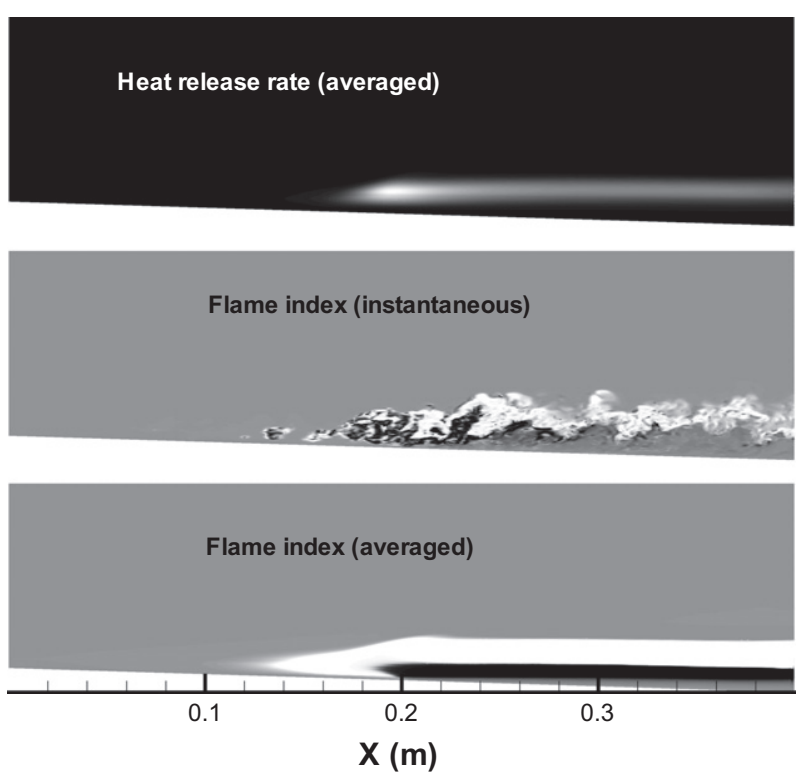

Fig. 10. Contours of flame index and heat release rate.

front from different directions), and premixed combustion (a positive flame index, as fuel and oxidizer approach the flame front from the same direction). The instantaneous structure indicates that non-premixed combustion dominates in the intense mixing zone downstream of the flame stabilization position. Fuel rich, premixed combustion takes place near the bottom wall, as the lifted flame allows hydrogen and oxygen to mix before being entrained into the reaction zone. The time-averaged flame index shows that a region of non-premixed combustion exists upstream of the point of maximum heat release, before the formation of the rich, premixed combustion region. As shown in the instantaneous contours of Figs. 6 and 10, this region is characterized by the intermittent formation of thin reaction zones and their extinguishment due to

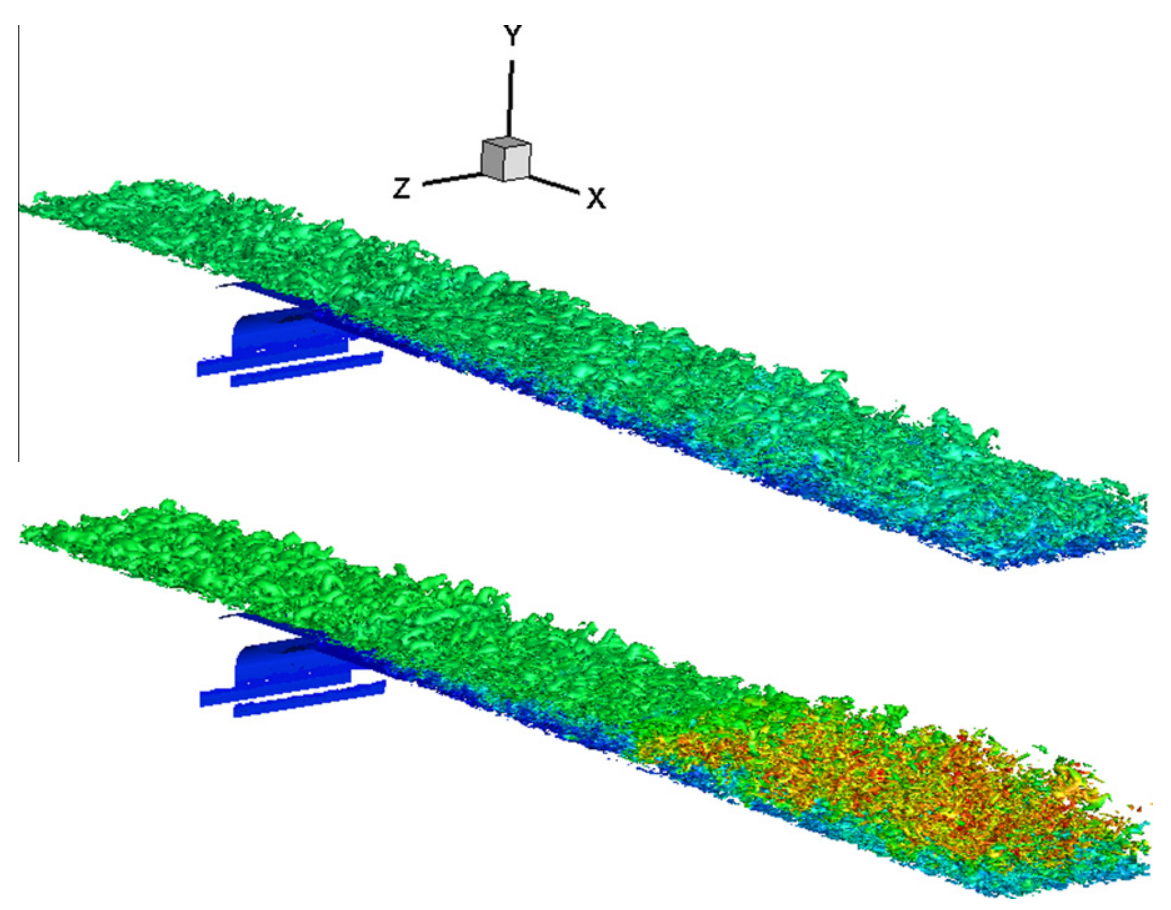

Fig. 9. Swirl-strength iso-surfaces (top - non-reacting, bottom - reacting, contours from 250 to $2500 \mathrm{~K}$ ). 
high turbulence-induced strain rates. As the shear layer spreads, local strain rates diminish and the reaction zones become more connected and more resistant to turbulent-eddy interactions. There is no evidence of a lean premixed branch, as one might expect in a laminar triple-flame structure, in either the time-averaged or instantaneous contours. A more sophisticated analysis, such as that proposed in [45], would be necessary to confirm the presence of this branch.

The sidewall and top boundary layers in the 3D domain range from 1 to $1.5 \mathrm{~cm}$ in thickness in the combustor section (see Fig. 11). These provide a displacement effect that acts to compress the flow further. The flame-anchoring position moves further upstream for the LES/RANS simulations performed on this domain, to $\sim 16 \mathrm{~cm}$ downstream of the fuel injector exit. Three-dimensional snapshots of temperature at different cross-stream planes in Fig. 11 illustrate the blockage effects of the sidewall boundary layers and also the large degree of variation in the reaction zone structure across the lateral extent of the combustor. Longitudinal vortical structures with sizes of the order of the shear layer thickness deform the flame front significantly in the cross-stream direction, though smaller-sized structures are also captured. The vertical extent of the reaction zone increases within the sidewall boundary layers, as shown in the time-averaged exit-plane temperature contours included as an inset figure. This effect is likely a result of counter-rotating corner vortices that act to force hot reaction products from the reaction zone toward the wall and into the corner. Average temperatures in the reaction zone are $\sim 1900 \mathrm{~K}$ - substantially less than the peak values of around $2500 \mathrm{~K}$ shown in the instantaneous snapshots. This effect is due to large-eddy interactions within the reactant streams which locally strain the flame, reducing the effective reaction rate, and also cool it through engulfment of colder pockets of fluid.

\subsection{Vitiated-air mixing and combustion - comparisons with experimental data}

Figure 12 presents stagnation temperature profiles at the combustor exit for the reactive cases. The solutions obtained on the

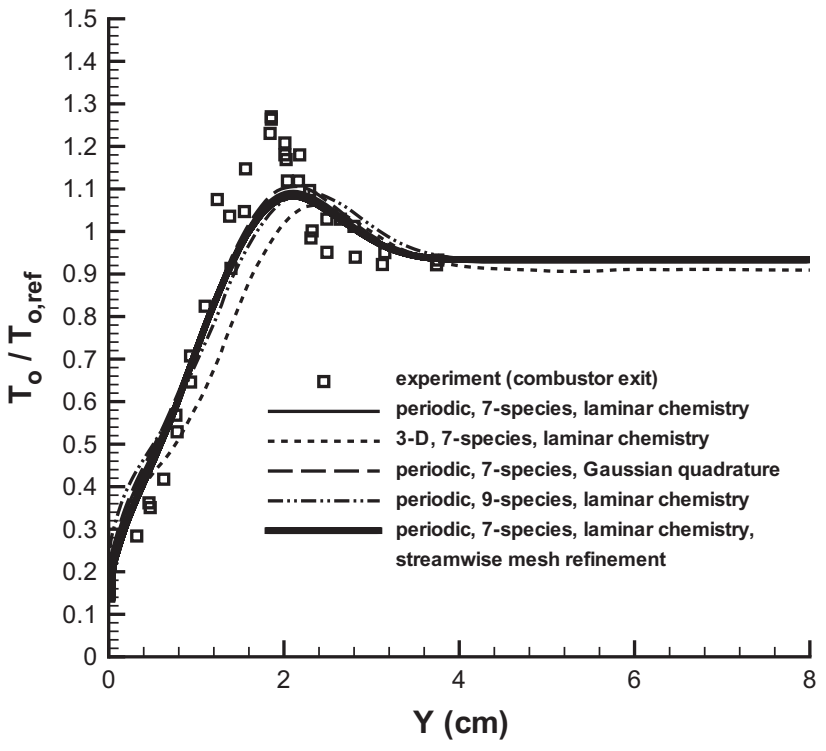

Fig. 12. Stagnation temperature profiles at combustor exit (vitiated-air mixing and combustion).

periodic domain under-predict the peak stagnation temperature but show reasonable agreement with the shear layer width. The effect of the Gaussian-quadrature subgrid model is to sharpen the stagnation-temperature peak slightly. The location of the peak is shifted further away from the wall for the solution obtained on the 3D domain. This effect may also be due to the corner vortices mentioned earlier, as these force fluid within the sidewall boundary layers downward into the corner, then laterally toward the centerline, and finally upward into the middle of the combustor. The nine-species reaction mechanism also results in a slight shift of the peak in stagnation temperature away from the wall. Pitot pressure profiles in Fig. 13 show similar trends. The shear layer appears to be further displaced from the lower wall for the solution

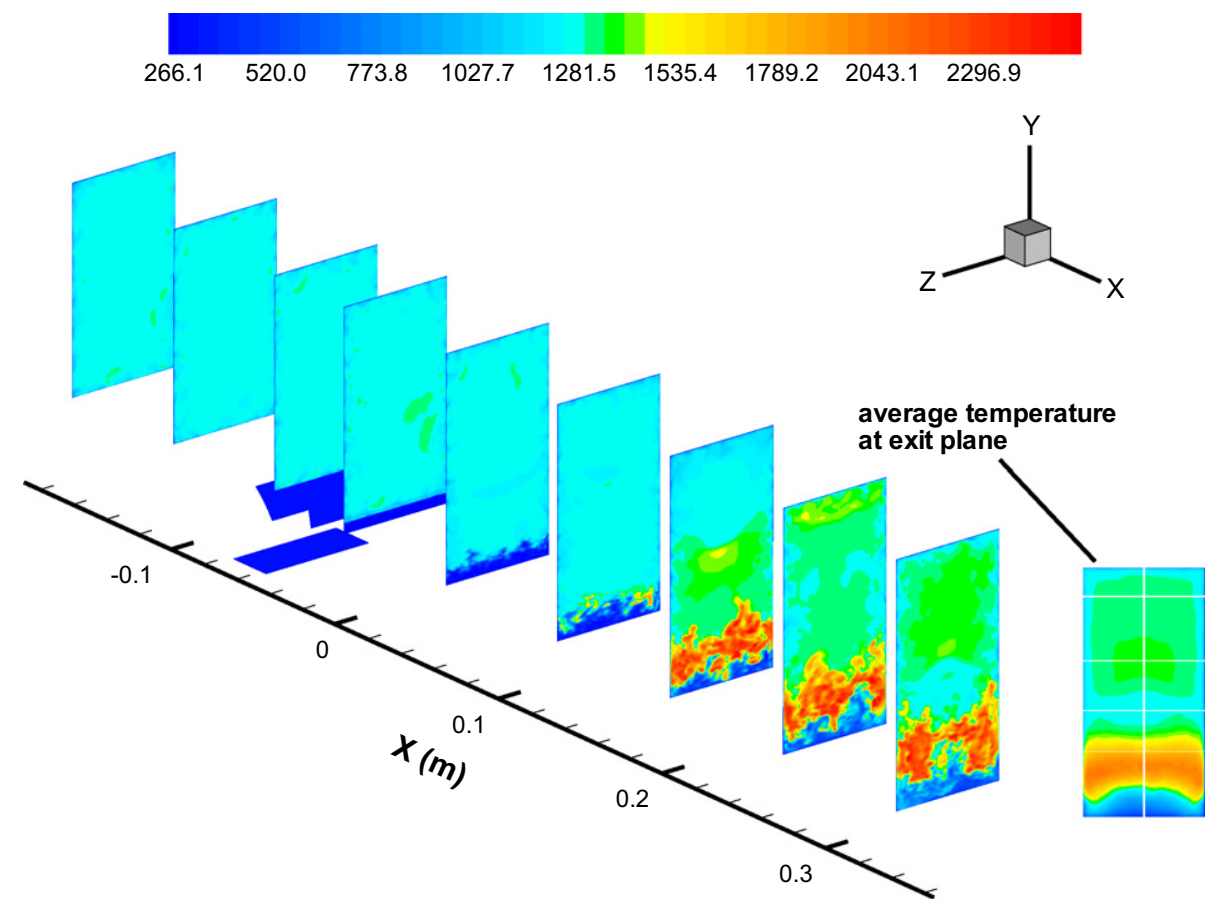

Fig. 11. Temperature contours at different cross-stream planes (3D domain, vitiated-air mixing and combustion) 


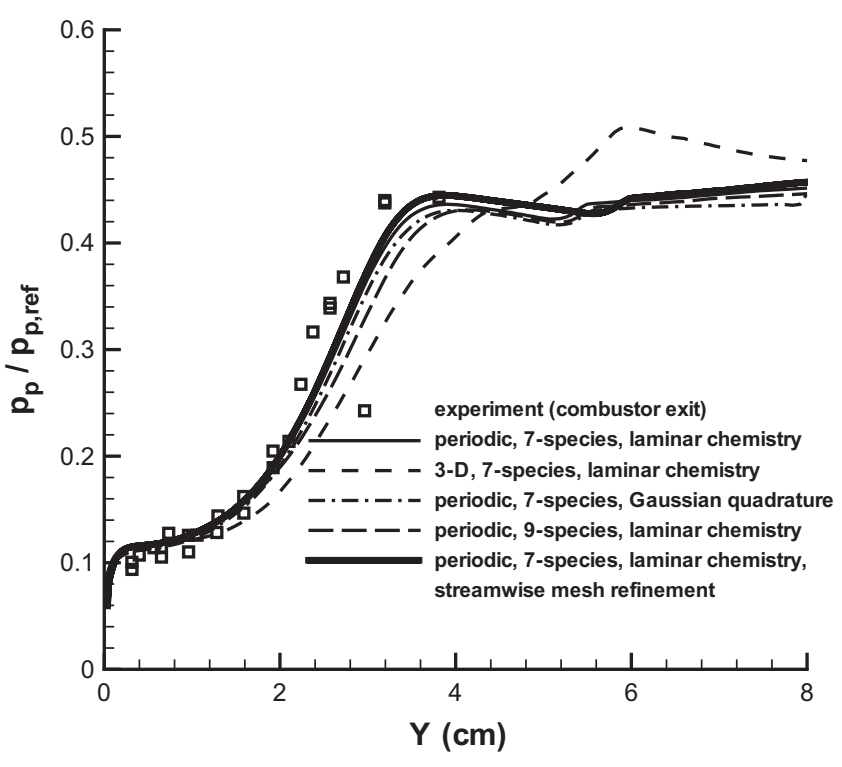

Fig. 13. Pitot pressure profiles at combustor exit (vitiated-air mixing and combustion).

obtained on the 3D domain. Traces of shock waves traversing the data plane are noted in the profiles.

Mole fraction profiles at $X=35.4 \mathrm{~cm}$ are shown in Fig. 14. The peak in water production is consistently under-predicted, though its location is reasonably well-captured by the solutions obtained on the periodic domain. The reaction zone is displaced further from the wall for the solution obtained on the 3D domain. This yields better agreement with experimental data for $Y<2 \mathrm{~cm}$ but the water mole-fraction peak deviates more from the measured location. The nine-species reaction mechanism provides a similar, but less pronounced shifting of the reaction zone. A slight increase in water production is predicted by the Gaussian quadrature model relative to the laminar chemistry model. This increase is associated primarily with the modest shifting of the flame stabilization position further upstream as noted in Fig. 7. In all cases, the time-averaged reaction zone appears broader than indicated in

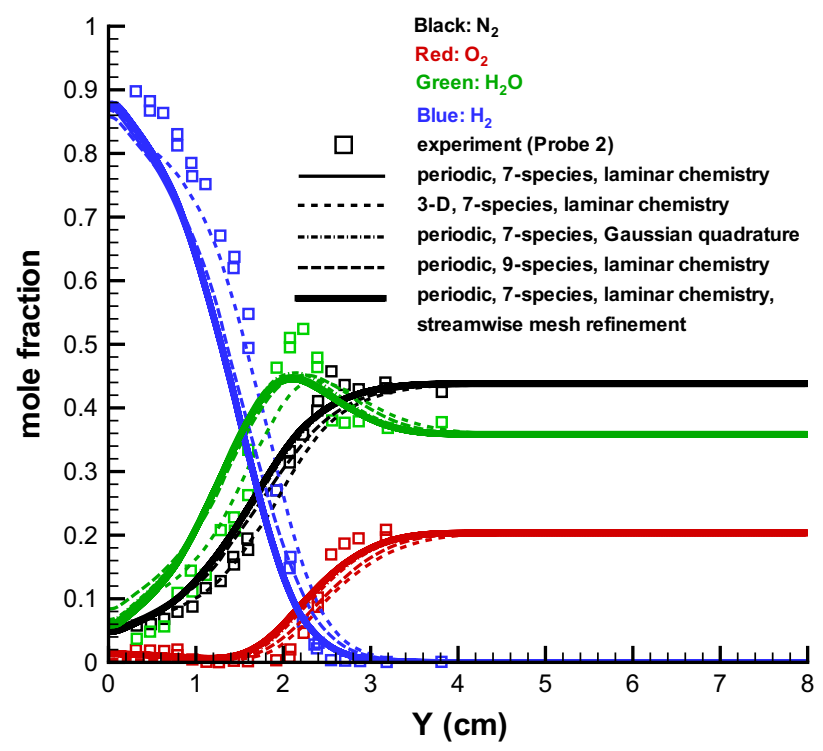

Fig. 14. Mole-fraction profiles at combustor exit (Probe 2, vitiated-air mixing and combustion) the experimental data. The experimental data shown in Fig. 14 is that most commonly used in prior computational comparisons [20-24]. Another set of mole-fraction measurements is also presented in [18], and a comparison of the LES/RANS results with this data set is shown in Fig. 15. In the report [18], water condensation within the sampling probe is given as a reason for the large water concentration levels, but it is interesting that the thickness of the time-averaged reaction zone as predicted by the LES/RANS models agrees quite well with these measurements, even though the vitiated-air composition is slightly different.

Figures 12-14 also show that streamwise mesh refinement for the seven-species, laminar chemistry calculation yields only minimal differences in the time-averaged predictions. The slight upstream shift in the flame-stabilization location evidenced in Fig. 7 alters the position of the generated shock wave (see Fig. 5). This primarily affects the Pitot pressure profiles (Fig. 13).

\subsection{Vitiated-air mixing and combustion - turbulence/chemistry interactions}

Scatter plots of reactive scalars versus mixture fraction can be used to assess the degree to which resolved turbulent eddies influence the flame behavior. The mixture fraction definition is based on the use of the hydrogen element fraction:

$f=\frac{e_{\mathrm{H}}-e_{\mathrm{H}, 1}}{e_{\mathrm{H}, 2}-e_{\mathrm{H}, 1}}$,

with the hydrogen element fraction defined in terms of the species mass fractions for the seven-species model as

$e_{\mathrm{H}}=Y_{\mathrm{H}_{2}}+Y_{\mathrm{H}_{2} \mathrm{O}} / 9+Y_{\mathrm{OH}} / 17+Y_{\mathrm{H}}$,

and the subscripts 1 and 2 representing the hydrogen and vitiatedair streams, respectively. The stoichiometric value of the mixture fraction $f_{s t}$ is found by considering combustion of hydrogen at the experimental fuel/vitiated-air ratio of 0.0143 according to the one-step, irreversible reaction

$\mathrm{H}_{2}+\frac{1}{2} \mathrm{O}_{2} \Rightarrow \mathrm{H}_{2} \mathrm{O}$.

The stoichiometric mixture fraction is a sensitive function of the fraction of unburned hydrogen assumed to be present after combustion,

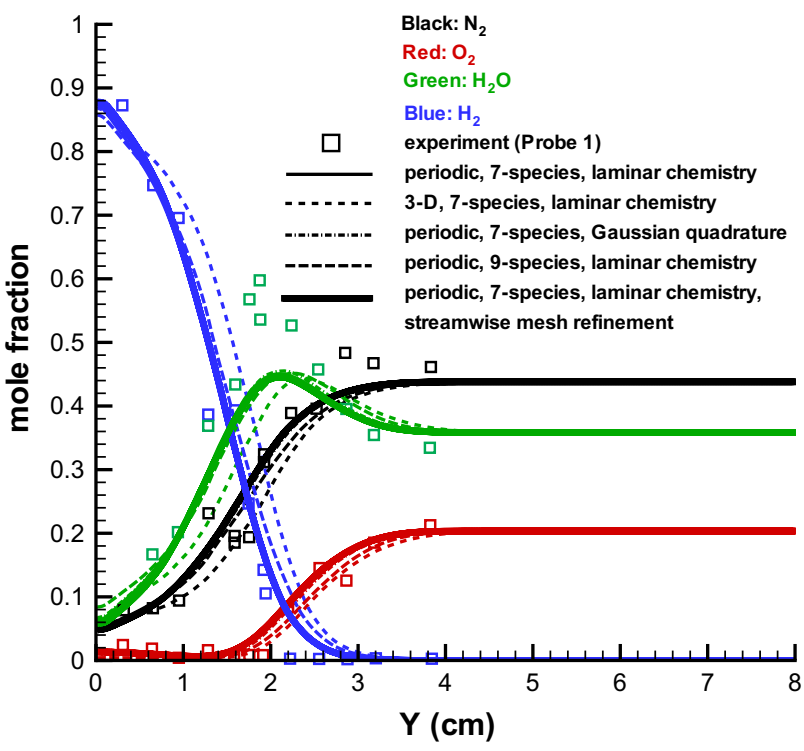

Fig. 15. Mole fraction profiles at combustor exit (Probe 1, vitiated-air mixing and combustion). 
with values ranging from 0.014 for $0 \%$ unburned hydrogen to 0.040 for $5 \%$ unburned hydrogen. The data used in the scatter plots was sampled from the seven-species solution on the periodic domain at four planes within the combustor - one well upstream of the ignition location $(X=9.95 \mathrm{~cm})$, one within the region of intermittent combustion noted in Figs. 5 and $6(X=20 \mathrm{~cm})$, one near the point of maximum heat release (Fig. 10, $X=22.6 \mathrm{~cm}$ ), and one near the measurement location of $X=35.4 \mathrm{~cm}$. Figure 16 a plots $\mathrm{O}_{2}$ and $\mathrm{H}_{2} \mathrm{O}$ mass fractions (left axis) and temperature (right axis) versus mixture fraction at the plane well upstream of the ignition location. The expected linear variation of species concentration with mixture fraction is recovered in this region. Within the intermittent region and just downstream (Fig. 16b and c), the scatter plots reveal a transition between an unburned flamelet structure and a burning flamelet structure. The significant levels of scatter indicate that transient ignition events are present in this region and that the lifted flame allows some oxygen and water vapor to mix with the hydrogen stream without passing through the reaction zone. Near the combustor exit (Fig. 16d), peaks in temperature and the minor species $\mathrm{OH}$ and $\mathrm{O}$ atom (not shown) are located within the range calculated above for the stoichiometric mixture fraction $(0.014-0.04)$. If the $\mathrm{OH}$ peak can be identified with the true stoichiometric mixture fraction contour, then the peak temperature values occur toward the fuel-rich side and the peak $\mathrm{O}$ atom values occur toward the fuel-lean side. Peak values of water and $\mathrm{H}$ atom (not shown) are located at higher (fuel rich) values of the mixture fraction. Flame-lift effects are indicated also at this station, as unburned oxygen and hydrogen are still present beneath the flame front. The scatter in the composition variables about mixture-fraction conditioned averages indicates the effect of turbulent-eddy interactions in locally straining the flame. These results provide evidence that a strained flamelet model for turbulent combustion may be valid in this region of the flame.

\section{Conclusions}

Simulations of the Burrows and Kurkov reacting wall-jet experiment using large-eddy/Reynolds-averaged Navier-Stokes (LES/ RANS) methods have been described in this paper. Calculations have been performed on an idealized 2D geometry, in which sidewall effects are neglected, and a fully 3D geometry, in which top and side-wall boundary layers are resolved. The LES/RANS model

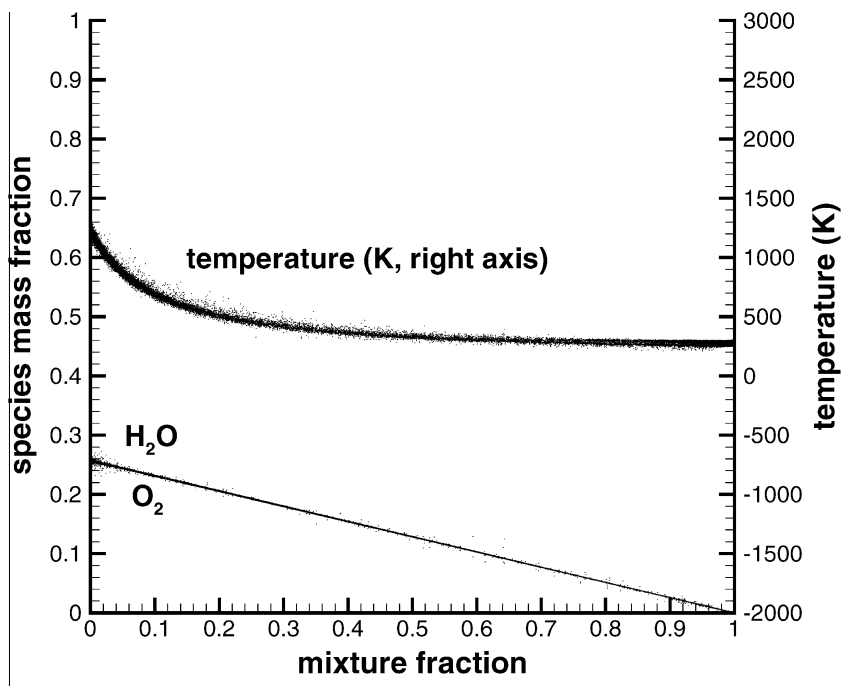

(a)

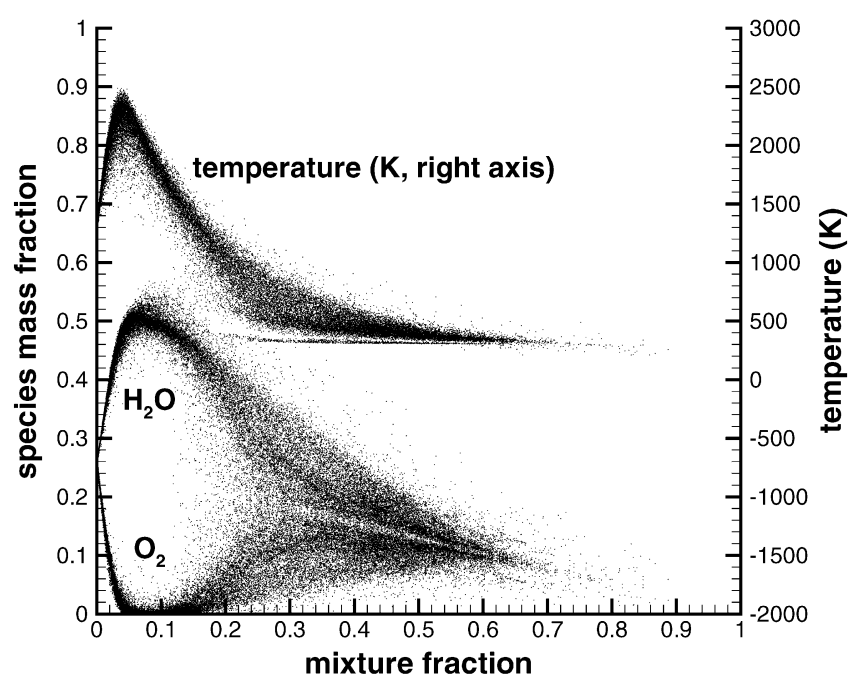

(c)

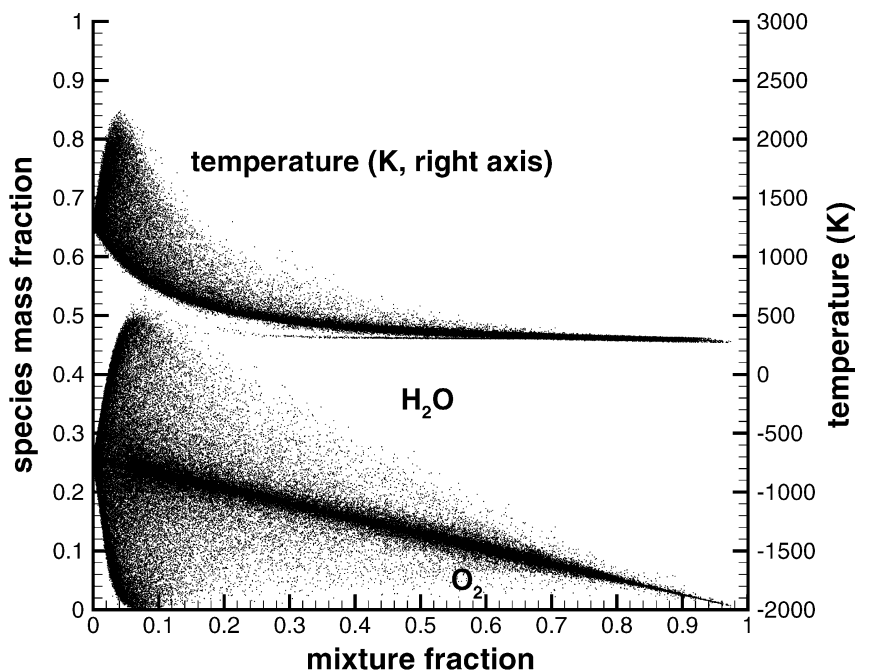

(b)

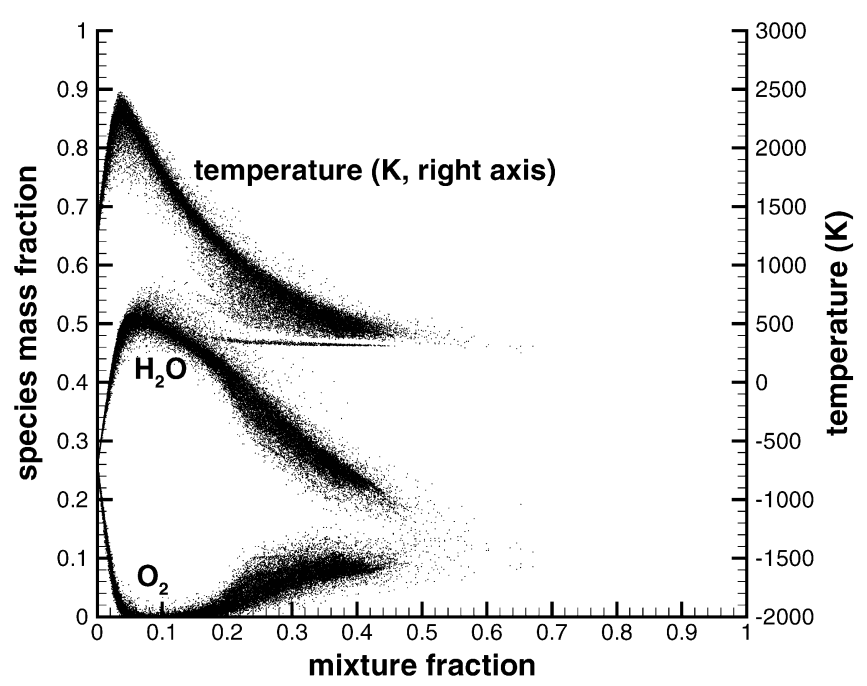

(d)

Fig. 16. Scatter plots of species mole fraction and temperature versus mixture fraction. 
provides good predictions of non-reactive mixing of the hydrogen jet and the vitiated-air stream. Simulations including chemical reactions predict a lifted flame, stabilized from 15 to $20 \mathrm{~mm}$ downstream of the injection location. The flame anchoring position moves toward the fuel injection location for calculations performed on the $3 \mathrm{D}$ domain, and the reaction zone structure is influenced by the formation of counter-rotating vortex pairs in the side-wall/lower-wall junctures. In all cases, the ignition event causes significant changes in the structure of the shear layer. Combustion-induced volumetric expansion leads to an enhanced growth rate of the shear layer and the formation of larger eddies that act to stretch the flame and to force large pockets of colder reactant fluid toward the flame front. The time-averaged reaction zone as predicted in the calculations performed on the 3D domain is shifted further away from the wall than indicated in the experimental data. This effect is due to the lifting action of a pair of counter-rotating vortices and may imply that the LES/RANS model over-predicts the growth rate of the sidewall boundary layers. As details of the facility nozzle are not known precisely, it is not surprising that idealized inflow conditions may lead to such discrepancies. All LES/RANS models under-estimate the peak levels of stagnation temperature and water concentration in the time-averaged reaction zone. This appears to be a consequence of too-rapid mixing of colder reactants at larger turbulence length scales. The use of a Gaussian quadrature estimate for the filtered species production terms provides a slight improvement in this regard. Reactive scalar scatter plots indicate that the flame exhibits a transition from a partially-premixed flame structure, characterized by intermittent heat release, to a diffusion-flame structure that could probably be described by a strained laminar flamelet model.

\section{Acknowledgments}

This work is supported by NASA under Cooperative Agreement NNX07AC27A-S01 and by the National Center for Hypersonic Combined-Cycle Propulsion, funded jointly by AFOSR and NASA. Computer resources have been provided by the NASA Advanced Supercomputing (NAS) division.

\section{Appendix A. Implementation of Gaussian quadrature model}

The implementation of the Gaussian quadrature model requires first a transformation into a uniform computational space, where the quadrature rules can be defined correctly:

$$
\begin{aligned}
\Omega \overline{\dot{\omega}_{s}} & =\iiint_{\Omega}(V(\vec{x})) d \Omega \approx \sum_{k=1}^{n q} w_{k} \dot{\omega}_{s}\left(V_{R}\left(\vec{x}_{k}\right)\right) \\
& =\sum_{k=1}^{n q} \tilde{w}_{k} J\left(\vec{x}_{k}\left(\vec{\xi}_{k}\right)\right) \dot{\omega}_{s}\left(V_{R}\left(\vec{x}_{k}\left(\vec{\xi}_{k}\right)\right)\right) .
\end{aligned}
$$

Here, $\vec{\xi}_{k}$ denotes a set of quadrature points

\section{Table A1}

Quadrature weights and locations.

\begin{tabular}{lllll}
\hline$k$ & $\xi$ & $\eta$ & $\zeta$ & $\tilde{w}_{k}$ \\
\hline 1 & $\frac{1}{2}\left(1-\frac{1}{\sqrt{3}}\right)$ & $\frac{1}{2}\left(1-\frac{1}{\sqrt{3}}\right)$ & $\frac{1}{2}\left(1-\frac{1}{\sqrt{3}}\right)$ & $1 / 8$ \\
2 & $\frac{1}{2}\left(1-\frac{1}{\sqrt{3}}\right)$ & $\frac{1}{2}\left(1-\frac{1}{\sqrt{3}}\right)$ & $\frac{1}{2}\left(1-\frac{1}{\sqrt{3}}\right)$ & $1 / 8$ \\
3 & $\frac{1}{2}\left(1-\frac{1}{\sqrt{3}}\right)$ & $\frac{1}{2}\left(1-\frac{1}{\sqrt{3}}\right)$ & $\frac{1}{2}\left(1-\frac{1}{\sqrt{3}}\right)$ & $1 / 8$ \\
4 & $\frac{1}{2}\left(1-\frac{1}{\sqrt{3}}\right)$ & $\frac{1}{2}\left(1-\frac{1}{\sqrt{3}}\right)$ & $\frac{1}{2}\left(1+\frac{1}{\sqrt{3}}\right)$ & $1 / 8$ \\
5 & $\frac{1}{2}\left(1+\frac{1}{\sqrt{3}}\right)$ & $\frac{1}{2}\left(1-\frac{1}{\sqrt{3}}\right)$ & $\frac{1}{2}\left(1+\frac{1}{\sqrt{3}}\right)$ & $1 / 8$ \\
6 & $\frac{1}{2}\left(1+\frac{1}{\sqrt{3}}\right)$ & $\frac{1}{2}\left(1+\frac{1}{\sqrt{3}}\right)$ & $\frac{1}{2}\left(1-\frac{1}{\sqrt{3}}\right)$ & $1 / 8$ \\
7 & $\frac{1}{2}\left(1+\frac{1}{\sqrt{3}}\right)$ & $\frac{1}{2}\left(1+\frac{1}{\sqrt{3}}\right)$ & $\frac{1}{2}\left(1+\frac{1}{\sqrt{3}}\right)$ & $1 / 8$ \\
8 & $\frac{1}{2}\left(1+\frac{1}{\sqrt{3}}\right)$ & $\frac{1}{2}\left(1+\frac{1}{\sqrt{3}}\right)$ & $\frac{1}{2}\left(1+\frac{1}{\sqrt{3}}\right)$ & $1 / 8$ \\
\hline
\end{tabular}

$\vec{\xi}=\xi, \eta, \zeta=[(0,1),(0,1),(0,1)]$,

defined in a computational space, $\tilde{w}_{k}$ are the quadrature weights in this space, $\vec{x}=x, y, z$, and $J\left(\vec{x}_{k}\left(\vec{\xi}_{k}\right)\right)$ is the Jacobian of the transformation. It is clear from the above equivalence that $w_{k}=\tilde{w}_{k} J\left(\vec{x}_{k}\left(\vec{\xi}_{k}\right)\right)$ and $\Omega=\sum_{k=1}^{n q} \tilde{w}_{k} J\left(\vec{x}_{k}\left(\vec{\xi}_{k}\right)\right)$. A set of quadrature weights and locations that integrate third-order polynomials exactly are listed in Table A1.

The Jacobian is defined by first considering a linear variation of $\vec{x}$ within a mesh cell:

$$
\begin{aligned}
\vec{x}(\xi, \eta, \zeta)= & \vec{a}_{1}+\vec{a}_{2} \xi+\vec{a}_{3} \eta+\vec{a}_{4} \varsigma+\vec{a}_{5} \xi \eta+\vec{a}_{6} \xi \zeta+\vec{a}_{7} \eta \zeta \\
& +\vec{a}_{8} \xi \eta \zeta,
\end{aligned}
$$

where

$$
\begin{aligned}
& \vec{a}_{1}=\vec{x}_{i-1, j-1, k-1}, \\
& \vec{a}_{2}=-\vec{a}_{1}+\vec{x}_{i, j-1, k-1}, \\
& \vec{a}_{3}=-\vec{a}_{1}+\vec{x}_{i-1, j, k-1}, \\
& \vec{a}_{4}=-\vec{a}_{1}+\vec{x}_{i-1, j-1, k}, \\
& \vec{a}_{5}=-\vec{a}_{2}+\vec{x}_{i, j, k-1}-\vec{x}_{i-1, j, k-1}, \\
& \vec{a}_{6}=-\vec{a}_{2}-\vec{x}_{i-1, j-1, k}+\vec{x}_{i, j-1, k}, \\
& \vec{a}_{7}=-\vec{a}_{3}-\vec{x}_{i-1, j-1, k}+\vec{x}_{i-1, j, k}, \\
& \vec{a}_{8}=-\vec{a}_{5}+\vec{x}_{i-1, j-1, k}-\vec{x}_{i, j-1, k}+\vec{x}_{i, j, k}-\vec{x}_{i-1, j, k} .
\end{aligned}
$$

From this, the Jacobian can be calculated as

$J=x_{\xi}\left(y_{\eta} z_{\zeta}-y_{\zeta} z_{\eta}\right)-x_{\eta}\left(y_{\xi} z_{\zeta}-y_{\zeta} x_{\xi}\right)+x_{\zeta}\left(y_{\xi} z_{\eta}-y_{\eta} z_{\xi}\right)$.

The physical locations corresponding to each quadrature location $\vec{\xi}_{k}=\xi_{k}, \eta_{k}, \zeta_{k}$ can be found by substituting the values in Table A1 into Eq. (A3). The cell centered value $\vec{x}_{0}$ can be determined by substituting the values $\xi=1 / 2, \eta=1 / 2, \zeta=1 / 2$ into Eq. (A3).

Cell-centered gradient information required in Eqs. (5) and (7) is calculated using Green's theorem:

$\Omega \nabla \bar{V}=\sum_{l} \bar{V}_{l} \vec{n}_{l} A_{l}$,

where $\vec{n}_{l}, A_{l}$ are cell-face unit normals and areas and $V_{l}=\frac{1}{2}\left(\bar{V}+\bar{V}_{N}\right)$. Here, $N$ refers to the face neighbor. The curvature term requires some assumptions to reduce the cost of the evaluation. First, we approximate $\nabla \bar{Q}, \quad \bar{Q}=\nabla \bar{V} \cdot\left(\vec{x}_{k}-\vec{x}_{0}\right)$ as

$\Omega \nabla \bar{Q}=\sum_{l} \bar{Q}_{l} \vec{n}_{l} A_{l}$

The vector $\bar{Q}$ is approximated at a cell interface by first associating the vector $\vec{x}_{k}-\vec{x}_{0}$ with that of the mesh cell in question. The gradient $\nabla \bar{V}_{l}$ at a cell interface is approximated as the directional derivative pointing from the mesh-cell to its face neighbor:

$\nabla \bar{V}_{l}=\frac{2\left(\bar{V}_{N}-\bar{V}\right)}{\Omega+\Omega_{N}} \vec{n}_{l} A_{l}$

This 'thin layer' approximation is adopted for reasons of simplicity and because nominally Cartesian mesh topologies are used in this work. As eight quadrature points are required for a hexahedral mesh cell, the Gaussian quadrature method requires eight evaluations of the chemical source terms per mesh cell.

\section{References}

[1] R.A. Baurle, AIAA Paper 2004-0267.

[2] F.A. Jaberi, P.J. Colucci, S. James, et al., J. Fluid Mech. 401 (1999) 85-121.

[3] S. Navarro-Martinez, A. Kronenburg, F. Di Mare, Flow, Turb., Combust. 75 (2005) 245-274.

[4] T. Echekki, A.R. Kerstein, T.D. Dreeben, Combust. Flame 125 (2001) 1083-1105.

[5] N. Peters, Turbulent Combustion, Cambridge University Press, 2000.

[6] C.D. Pierce, P. Moin, J. Fluid Mech. 504 (2004) 73-97.

[7] F. Genin, B. Chernyavsky, S. Menon, AIAA Paper 2003-7035.

[8] F. Genin, S. Menon, AIAA Paper 2009-132.

[9] M. Berglund, C. Fureby, Proc. Combust. Inst. 31 (2007) 2497-2504.

[10] S. Menon, P.A. McMurtry, A.R. Kerstein, AIAA Paper 1993-107. 
[11] W. Waidmann, F. Alff, U. Brummund, M. B'ohm, W. Clauss, M. Oschwald, Space Technol. 15 (1995) 421-429.

[12] M. Berglund, C. Fureby, V. Sabel'nikov, J. Tegner, 32nd International Symposium on Combustion, Montreal, Canada, Paper 1E12, August, 2008.

[13] D.M. Peterson, G.V. Candler, AIAA Paper 2008-6923.

[14] D.M. Peterson, G.V. Candler, AIAA Paper 2009-0130.

[15] S. O'Byrne, P.M. Danehy, A.D. Cutler, AIAA Paper 2004-0710.

[16] P. Donde, H. Koo, V. Raman, AIAA Paper 2010-0203.

[17] J.R. Edwards, J.-I. Choi, J.A. Boles, AIAA J. 46 (2008) 977-991.

[18] M.C. Burrows, A.P. Kurkov, Supersonic Combustion of Hydrogen in a Vitiated Air Stream using Stepped Wall Injection, NASA-TM-X-67840, 1971.

[19] M.C. Burrows, A.P. Kurkov, Analytical and Experimental Study of Supersonic Combustion of Hydrogen in a Vitiated Airstream, NASA-TM-X-2828, 1973.

[20] P.G. Keistler, R.L. Gaffney, X. Xiao, H.A. Hassan, AIAA Paper 2005-5382.

[21] W. Engblom, F. Frates, C.C. Nelson, AIAA Paper 2005-1000.

[22] M. Deepu, S. Gokhale, S. Jayaraj, J. Combust. Soc. Jpn. 48 (2006) 187-197.

[23] K. Brinckman, W.H. Calhoon, S.M. Dash, AIAA J. 45 (2007) 1036-1046.

[24] H.B. Ebrahimi, AIAA-1993-1840.

[25] J.P. Drummond, R.C. Rogers, Comp. Methods Appl. Mech. Eng. 64 (1987) 39-60.

[26] D.R. Eklund, S.D. Stouffer, AIAA Paper 94-2819.

[27] C.J. Jachimowski, An Analysis of Combustion Studies in Shock/Expansion Tunnels and Reflected Shock Tunnels, NASA TP-3224, 1992.
[28] B.J. McBride, S. Gordon, M.A. Reno, Coefficients for Calculating Thermodynamic and Transport Properties of Individual Species, NASA TM-4513, 1993.

[29] J.-I. Choi, J.R. Edwards, R.A. Baurle, AIAA J. 47 (2009) 2179-2193.

[30] J.A. Boles, J.-I. Choi, J.R. Edwards, R.A. Baurle, AIAA Paper 2009-1324.

[31] S. Ghosh, J.-I. Choi, J.R. Edwards, J. Prop. Power 26 (2010) 203-214.

[32] F.R. Menter, AIAA J. 32 (1994) 1598-1605.

[33] E. Lenormand, P. Sagaut, L. Ta Phuoc, P. Comte, AIAA J. 38 (2000) 1340-1350

34] L.G. Margolin, M. Shashkov, Int. J. Numer. Methods Fluids 58 (2008) 991-1002.

35] P.E. DesJardin, S.H. Frankel, Phys. Fluids 10 (1998) 2298-2314.

[36] J.A. Boles, J.-I. Choi, J.R. Edwards, R.A. Baurle, AIAA Paper 2010-1099.

37] P. Colella, P.R. Woodward, J. Comput. Phys. 54 (1984) 174-201.

[38] J.R. Edwards, Comput. Fluids 26 (1997) 635-659.

[39] A. Jameson, J. Sci. Comput. 34 (2008) 188-208.

40] P.K. Subbareddy, G.V. Candler, J. Comput. Phys. 228 (2009) 1347-1364.

41] F. Ducros, V. Ferrand, F. Nicaud, C. Weber, D. Darracq, C. Gachareiu, T. Poinsot, J. Comput. Phys. 152 (1999) 517-549.

[42] E. Garnier, Shock Waves 19 (2009) 479-486

43] J.B. Star, J.R. Edwards, M.K. Smart, R.A. Baurle, AIAA Paper 2006-3040.

[44] H. Yamashita, M. Shimada, T. Takeno, Proc. Combust. Inst. 26 (1996) 27-34.

[45] T. Lu, C.S. Yoo, J.H. Chen, C.K. Law, AIAA Paper 2008-1013. 